\title{
LOS MOVIMIENTOS OBREROS ESPECIALIZADOS DE ACCIÓN CATÓLICA \\ DE LA DIÓCESIS DE CÁDIZ: JOC Y HOAC. \\ UNA APROXIMACIÓN HISTÓRICA Y APOSTÓLICA
}

\author{
FrANCISCO JAVIER TORRES BARRANCO \\ UNED
}

RESUMEN: El presente estudio indaga en aquellos hitos históricos más relevantes de la JOC y la HOAC de la diócesis de Cádiz que permiten entender cómo estos movimientos, nacidos de la Iglesia, intentaron, sin ser ni un partido político ni un sindicato, promocionar a la clase trabajadora gaditana por medio de acciones, no solo formativas, que contribuyeran a su empoderamiento.

El apoyo institucional, personificado en la figura del obispo Añoveros, hizo que sus actividades fueran no solo conocidas en los ambientes obreros gaditanos, sino que gozaran, además, de prestigio, incluso en los años de la crisis de Acción Católica.

PALABRAS CLAVE: JOC, HOAC, diócesis de Cádiz, Miguel Mougán.

\section{SPECIALIZED LABOR MOVEMENTS OF ACCIÓN CATÓLICA IN THE DIOCESE OF CADIZ: JOC AND HOAC. A HISTORICAL AND APOSTOLIC APPROACH}

\begin{abstract}
The present research focuses on the most important moments of the JOC and HOAC of the Diocese of Cadiz that allow to understand how these movements, born of the Church, tried, without being neither a political party or a trade union, to promote the working class of Cadiz through actions, not only training actions, in order to contribute to their empowerment.

The institutional support, personified in the figure of the bishop Añoveros, allow that their activities were known in Cadiz workers environments with a good reputation, even in those years of the well known Acción Catolica crisis.
\end{abstract}

KEYWORDS: JOC, HOAC, diocese of Cadiz, Miguel Mougán.

Recibido: 14-09-2015 / Aceptado: 08-12-2015 


\section{INTRODUCCIÓN}

En las últimas décadas se asiste a un gran interés investigador y divulgativo sobre el papel de la Iglesia española en el periodo franquista, centrándose los estudios publicados tanto en dar a conocer la importancia que tuvo el catolicismo en la construcción de la democracia y posterior transición española como, fundamentalmente, por indagar en el aporte de los movimientos cristianos implicados pertenecientes al mundo obrero como oposición al Régimen de Franco en los años inmediatamente anteriores y posteriores al Concilio Vaticano II. ${ }^{1}$

De entre estos movimientos, destacan sobremanera tanto la HOAC (Hermandad Obrera de Acción Católica) como la JOC (Juventud Obrera Cristiana), que como movimientos especializados obreros de Acción Católica, trataron de introducir a la Iglesia en el alejado mundo obrero mediante acciones que no debían basarse en la pretensión de ganar obreros para Cristo, sino en ayudar al trabajador en su promoción social. Esta nueva forma de humanismo tenía el objetivo de "la consecución de la dignidad obrera, frase equivalente a la de conciencia de clase o a la de orgullo de clase". ${ }^{2}$

El estudio, aunque parte de los inicios históricos de los movimientos en la diócesis gaditana, profundiza en el periodo comprendido entre 1966 y 1971, momentos en que, a nivel nacional, se asiste a un distanciamiento y oposición al Régimen de Franco comúnmente llamado "despegue" y que responde a un doble proceso: por un lado, el alejamiento crítico de las organizaciones seglares con el nacionalcatolicismo que llega a su punto álgido con la llamada crisis de la Acción Católica de 1966, y, por otro, el despegue de la Iglesia institucional, cuyo cénit se representó en la Asamblea Conjunta de obispos y sacerdotes de septiembre de $1971 .^{3}$

\footnotetext{
${ }^{1}$ Valga como ejemplo el trabajo que realiza el Seminario de Estudios de Franquismo y Transición de la Universidad de Castilla-La Mancha, contribuyendo a la organización de seminarios y a la publicación de obras sobre este papel de la Iglesia católica como: ORTIZ HERAS, Manuel y GONZÁLEZ MADRID, Damián, (coord.), De la cruzada al desenganche: la Iglesia española entre el franquismo y la transición, Madrid, Sílex, 2011, que ya en la introducción habla del gran número de estudios locales y regionales sobre estas cuestiones ("lluvia fina" de estudios llega a decir, categoría en la que pretende instalarse el presente estudio).

${ }^{2}$ GÓMEZ RODA, J. Alberto, Comisiones Obreras y represión franquista. Ed. Universidad de Valencia, Valencia, 2004. p. 63.

${ }^{3}$ MONTERO, Feliciano, "La Iglesia en el tardofranquismo o el "despegue" de la Iglesia", Historia del presente, 10, 2007/2 II época, p.3.
} 
Para documentar las ideas anteriores en el territorio gaditano, especial atención se ha dedicado al estudio de la profusa documentación recopilada por de uno de los mayores protagonistas de la JOC y la HOAC en la diócesis, Miguel Mougán Guerrero ${ }^{4}$, conservada en el Seminario Diocesano San Bartolomé de Cádiz y que responden a dos bloques distintos denominados por el propio Mougán:

- Apuntes para una Historia de la HOAC de Cádiz. Distribuida por años y numerada por hechos y acontecimientos relevantes.

- Apuntes para la Historia de la JOC en Andalucía en su primer periodo: 19581971. También distribuida por años y eventos.

Esta documentación adquiere mayor importancia si cabe cuando se recuerda que el propio archivo general de la HOAC presenta lagunas importantes debido a la desaparición de documentos, bien porque muchos de ellos se confeccionaron para la lucha obrera concreta del momento, sin pensar que en un futuro podría hacerse pública la historia de la organización o, simplemente, porque la vigilancia policial obligó a quemarlos. ${ }^{5}$

\footnotetext{
${ }^{4}$ Nombrado el 20 de octubre de 1967 por el obispo Añoveros "Consiliario Diocesano de Movimientos Especializados Masculinos y Femeninos de la HOAC y la JOC". Por entonces, era etiquetado como: "Sacerdote progresista, beligerante con los conservadores" Archivo Histórico Provincial de Cádiz (desde ahora AHPC), Gobierno Civil (desde ahora GC), Orden Público y Derechos Ciudadanos (desde ahora OPyDC), Caja 2939, Carpeta 3.4. Asuntos Religiosos (desde ahora AR): Nota informativa del Cuerpo General de Policía de 8 de noviembre de 1971. E incluso: "Posible cerebro de todas las actividades subversivas (...) y persona sumamente peligrosa y astuta". AHPC, GC, OPyDC., Caja 2943. Carpeta 3.4. AR.: "Relación de sacerdotes contestatarios e implicados en alguna actividad política", nota informativa de la Policía 1 de diciembre de 1973, hoja 4.

${ }^{5}$ DÍAZ SALAZAR, R., Iglesia, Dictadura y Democracia, HOAC, Madrid, 1981, pp. 201-202.
} 


\section{CONTRIBUCIÓN DE LOS MOVIMIENTOS ESPECIALIZADOS AL MOVIMIENTO OBRERO GADITANO}

Tanto la $\mathrm{HOAC}^{6}$ como la $\mathrm{JOC}^{7}$ basaron sus esfuerzos de conquista de la justicia en el mundo obrero y de defensa del trabajador en la formación de militantes. Entendiendo que este proceso de enseñanza-aprendizaje debía realizarse mediante una nueva y moderna cultura democrática y participativa del propio trabajador, con la seguridad de que tales valores adquiridos dentro de los movimientos católicos contaminarían positivamente al movimiento obrero cuando esos mismos militantes tomaran parte en eventuales acciones sindicales, políticas o culturales.

Descendiendo al territorio gaditano, se puede estructurar la aportación concreta de HOAC y JOC diocesana en dos apartados:

Respecto del clero gaditano:

- Creación de un armazón de cobertura ideológica, doctrinal y teológica de aquellos sacerdotes diocesanos progresistas interesados en la problemática obrera, ya que, como tales movimientos, fueron una fuente inagotable de información fidedigna sobre el mundo obrero al clero gaditano, desde su base hasta la cúspide jerárquica diocesana.

- Ser una cantera efectiva para la formación de los futuros curas obreros.

Respecto del movimiento obrero gaditano en general. Se pueden destacar:

- Facilitar lugares de reunión lo suficientemente seguros como para albergar encuentros, debates y preparación de acciones de reivindicación socio laboral y

\footnotetext{
6 Para conocer la historia de la HOAC nacional, es imprescindible acudir a las obras pioneras de la historiadora y militante hoacista: LÓPEZ GARCÍA, B.: Aproximación a la historia de la HOAC, 1946-1981, HOAC, Madrid, 1995 y de FERRANDO BADÍA E.: FERRANDO, E.: "Origen y primeros pasos de la HOAC”, XX Siglos, 7 (1991), pp. 114-136. A nivel gaditano, aunque el documento es más que un referente historiográfico una exaltación de las siglas HOAC, interesa leer la Carta Pastoral del Obispo de Cádiz y Ceuta Antonio Ceballos Atienza de 8 de diciembre de 1996. Para el obispo, su aportación principal fue conseguir "palmo a palmo la superación del alejamiento hasta llegar al encuentro del mundo obrero y de la Iglesia". HOAC: cincuenta años de encuentro entre la Iglesia y el mundo obrero, Servicio de Publicaciones del Obispado de Cádiz y Ceuta, Cádiz, 1996.

7 Para conocer a la JOC española desde sus inicios, baste con revisar la tesis doctoral de Francisco Martínez Hoyos: Cristianos y cristianas en la lucha obrera. Aproximación a la bistoria de la JOC/F en Barcelona durante los años sesenta, Universidad de Barcelona, 1999. Así se podrá acceder a conocer al perfil del jocista como el de un joven autodidacta que leía tanto el Evangelio como la historia del movimiento obrero y que completó su formación como militante de tal movimiento gracias a la reflexión que practicaba en las sesiones grupales.
} 
prestar sus instalaciones como lugar de salvaguardia de material de propaganda sindical, llegando a convertirse estas instalaciones en auténticas bibliotecas de material subversivo. ${ }^{8}$

- Contribuir con herramientas efectivas para el análisis de la realidad socio-laboral basadas en la discusión grupal por medio de la puesta en práctica de la revisión de vida obrera ${ }^{9}$ y el diseño de encuestas.

- Denuncias de las injusticias en el terreno laboral, fundamentadas en una Doctrina Social de la Iglesia que abogaba por valores solidarios y democráticos, y basadas en el principio de denuncia profética.

- Contribuciones directas hacia el beneficio de las condiciones laborales y sociales de los obreros gaditanos. Aunque se pueden documentar decenas de casos, sirvan como ejemplos las dos acciones que siguen:

Durante el verano de 1971 el Equipo de la HOAC de Cádiz trabajó durante semanas en diseñar un dato importante a la hora de negociar el Convenio Colectivo de Astilleros que sirviera de base para la reclamación salarial: el del "gasto mínimo diario" de una familia, que se cifró en 427,40 pesetas. $^{10}$

Algunos de los trabajadores que se dedicaban al rascado de pinturas en los cascos de los buques de Astilleros empezaron a padecer molestias serias por los gases que inhalaban. Los militantes hoacistas intentaron organizar una actuación de protesta, contando para ello con el ofrecimiento desinteresado de un simpatizante de la HOAC, médico de El Puerto de Santa María, que se ofreció a realizar y certificar todos los análisis que se hicieran necesarios. Desafortunadamente, después de varios intentos y entrevistas, se desistió la denuncia por el recelo y miedo que los obreros tenían de represalias de sus empresas. ${ }^{11}$

\footnotetext{
${ }^{8}$ Eran momentos en que el marxismo empezaba a ser entendido como una herramienta útil como método de análisis de la realidad social para las organizaciones católicas y el diálogo intelectual cristiano-marxista facilitaban el proceso de reconversión o conversión, según casos, de la militancia y de los intelectuales cristianos. CASTELLS, J., HURTADO J., Y MARGENAT, J.M., (eds.), De la dictadura a la democracia. La acción de los cristianos en España, Desclée de Brouwer, Bilbao, 2005

${ }^{9}$ Método especial de formación de los grupos de militantes y simpatizantes creada por la JOC y basada en la reflexión sobre la vida y la experiencia cotidiana de jóvenes obreros gracias a la pedagogía del ver, juzgar y actuar. Herramienta básica en el trabajo grupal jocista que se convierte en la forma habitual de análisis de la realidad y que trataba de responder a los problemas obreros con eficacia.

${ }^{10}$ Archivo personal de Miguel Mougán (desde ahora AMM): Datos para una historia de la HOAC de Cádiz. 1946-1984, Seminario diocesano de Cádiz San Bartolomé: "Trabajo de la HOAC para facilitar un dato importante a la hora de negociar el convenio colectivo de Astilleros", verano de 1971.

11 AMM, Datos para una historia de la HOAC...: "Problema que surgió entre algunos trabajadores de Astilleros", 1971.
} 
Con el bagaje citado, se favoreció en el territorio gaditano a la formación de líderes de los movimientos obreros en el seno de la propia empresa, llegando a gozar algunos de los militantes de tanta confianza para los demás compañeros trabajadores que en cualquier asunto de índole sindical surgido, se acudía y se consultaba con ellos. Con esas prácticas, muchos de ellos acabarían, por ejemplo, en CC.OO o USO ${ }^{12}$, estimulando a la clase obrera en la lucha política contra el Régimen, lo que ayuda a entender por qué el franquismo puso tanto empeño en perseguir y controlar a los militantes de HOAC y JOC en la diócesis de Cádiz ${ }^{13}$. Al desarrollo de lo hasta aquí esbozado, se dedican las siguientes páginas.

\section{EL DEVENIR HISTÓRICO DE LA HOAC Y LA JOC GADITANA}

\subsection{La génesis de los movimientos}

Hay que buscarla en el nacimiento de la JOC en el Campo de Gibraltar, en la barriada de La Colonia de la Línea de la Concepción, en 1948, porque es precisamente allí donde estaba por entonces Miguel Mougán Guerrero de párroco. En el patio de su iglesia se realizaban las reuniones donde, anecdóticamente, un grupo de jóvenes pintó el escudo jocista aunque de la JOC solo conocieran su nombre, aún no su metodología, pues aún eran poco más que una peña de amigos de la parroquia.

Ya en 1959 empiezan a funcionar, también en La Línea, grupos de JOC en la parroquia de Santiago, con Mougán a la cabeza, y en otras modestas y obreras como La Atunara. También en Puente Mayorga, en San Roque, con curas como Diego Sánchez y Antonio Alcedo. En Algeciras, hacia 1961 fue en la popular parroquia de la Bajadilla donde el párroco Manuel Galtier inició grupos de JOC. Por entonces era responsable de la sección masculina un mecánico (Pepe Llave) y de la JOCF (sección femenina del movimiento), una dependienta (Ana Benítez). Más tarde se formaron nuevos grupos en las también modestas barriadas de la Piñera y La Granja.

\footnotetext{
12 Para corroborar que en los aspectos citados hasta ahora no se difieren de las aportaciones en otros territorios, ha sido fundamental la lectura de la obra dedicada a la diócesis sevillana: HURTADO SÁNCHEZ, José, La Iglesia y el movimiento obrero de Sevilla (1940/1977). Antropología política de los cristianos de izquierda, Fundación el Monte, Sevilla 2006.

${ }^{13}$ De forma muy esquemática pero muy clarificadora, se sitúa el análisis histórico que relaciona a la iglesia popular con el movimiento obrero gaditano, la promoción de las clases populares y su compromiso con la democracia las obras de: MILLÁN CHIVITE, José L., en: Historia de Cádiz. Cádiz Siglo XX. Súlex, Madrid 2005, pp. 881-892 y FAJARDO SÁNCHEZ J. y BURGUILLOS PATRÓN F.: Historia del Movimiento Obrero. Las Comisiones Obreras de Cádiz, Cádiz. CC.OO, 2007, pp. 161-167.
} 
El 15 de septiembre de 1962, en la visita de Alberto Revuelta, vicepresidente nacional de la JOC, a La Línea de la Concepción, se pone en marcha el Equipo Federal del Campo de Gibraltar, integrado por Francisco Bazán, de La Línea, José Llaves, de Algeciras y Miguel Mougán, de consiliario. Al que se une, más tarde, la JOC de Los Barrios.

Los inicios gaditanos de la HOAC también ocurren en el municipio de La Línea, donde a partir del invierno de 1952, se empezó a formar un grupo con Miguel Mougán como consiliario y Cecilio Sánchez Juárez, obrero que trabajaba de mecánico en el arsenal de Gibraltar y algunos otros trabajadores del barrio de La Colonia, Parroquia del Sagrado Corazón, Crescencio y El Vizcaya. Las reuniones tenían lugar en los locales parroquiales de La Colonia y, algunas fechas después, en el Barrio del Castillo de España, donde tenían lugar en un cobertizo-carpintería, en la Parroquia de Santiago, contando entonces con una decena de trabajadores.

\subsection{La primera etapa: Etapa formativa (1950-1964)}

Los inicios del trabajo de la HOAC coinciden con los llamados "Círculos de Estudios"14, reuniones formativas que, en sus conclusiones, empiezan a conformar un análisis fiel de la realidad del obrero gaditano que les presenta como:

Bajo nivel espiritual del trabajador, ya fuera porque al salir de la escuela no iban más a los actos religiosos o porque se contagiaban en el taller y la fábrica de falsas doctrinas.

Los obreros miraban a Cristo como hombre que dio su vida en defensa de un alto ideal mientras a la Iglesia la miraban como un negocio.

Jesucristo vivió la vida ordinaria de un trabajador, formando el Colegio Apostólico a base de trabajadores, sin pensar nunca en fundar una religión solo de ricos.

Necesidad de predicar el Evangelio en los centros de trabajo.

Impulsar una más justa distribución de las riquezas y denuncia de la situación de la vivienda, para "así ser dignos de merecerse el título de cristianos".

Necesidad en la asociación de "hombres de acción", y no de "ratones de sacristía"

Tabla núm. 1: Conclusiones de los primeros Círculos de Estudios Fuente: Elaboración propia a partir de los primeros once Círculos de Estudios. Archivo personal de Miguel Mougán.

El aspecto que más merece la pena destacar de este periodo es el intento práctico, en 1963, de coordinación entre diversos grupos dedicados al Apostolado Obrero: HOAC, JOC, VOS (Vanguardia Obrera Social) y VOJ (Vanguardia Obrera Juvenil, organizadas por los

\footnotetext{
${ }^{14}$ Respecto de la capital gaditana, las temáticas sobre las que giraron la primera decena de estos encuentros formativos celebrados en Cádiz, ya fuera en la sede de la Calle San Francisco de Cádiz o en las prestadas instalaciones del Balón de Cádiz C.F., fueron diversas: la vida espiritual del hoacista, la ausencia de nivelación entre precios y salarios o la vivienda obrera, no contando por entonces con más de siete u ocho asistentes.
} 
jesuitas). Así, se empezaron a tener reuniones conjuntas de periodicidad mensual, turnándose la celebración en cada uno de los centros de los respectivos grupos. De las conclusiones extraídas de sus sesiones de trabajo, destacan aquellas que mostraban el interés por solidificar el sentido de pertenencia a la clase obrera y aquellas otras dirigidas a mostrar cómo debía ejercitarse la presencia obrera en la lucha por sus reivindicaciones, acordando que su presencia obrera como Apóstoles de Cristo estaba en:

Buscar la verdad entre los obreros, respetar a la persona, aunque no comulguen con nuestras ideas (...) debemos de darnos a respetar, para que puedan ellos ver en nosotros que también además de ser de Cristo vemos las cosas buenas y malas (...) Siendo la misión de los hoacistas gaditanos poder pasar a la masa obrera por el filtro de lo sindical a lo cristiano, debiendo consistir su forma de actuar en preguntarse antes de ofrecer cualquier tipo acción, de orientación o de consejo: "si Cristo estuviera presente ¿haría lo mismo?". 15

Por su parte, la JOC gaditana trataba en esta primera época de mostrar la especificidad del mundo del trabajo en que debía desenvolverse el joven trabajador de la diócesis, profundizando en aquella paradoja que lo mostraba como una persona que estaba en el mundo obrero físicamente presente, pero humanamente desplazado, lo que hacía de freno para la marcha del movimiento obrero ${ }^{16}$. La razón a este hecho era que los deseos del joven trabajador de "sentirse alguien" permanecían ahogados en su interior por unas condiciones de trabajo que impedían el desarrollo de sus cualidades profesionales y humanas y por una falta de preparación y competencia para hacer frente a esas condiciones. Ante esta realidad alienante, el joven trabajador sufría interiormente una decepción y frustración en sus más profundas aspiraciones que le dejaba amargado y sin alegría, acabando por tomar actitudes de conformismo, evasión e individualismo que le incapacitaban para avanzar en su vida y hacer algo por los demás.

\footnotetext{
15 AMM: Datos para una historia de la HOAC...: "Reunión conjunta", mayo de 1962.

${ }^{16}$ Tesis que defiende el Responsable de Zona, Manuel Cota Maximiliano en un escrito enviado a las bases que contenía consideraciones acerca de los problemas que hacían que los jóvenes trabajadores no estuvieran plenamente integrados en el mundo del trabajo. En: AMM: Apuntes para la Historia de la JOC...: "Hacia una presencia activa y responsable en la vida de trabajo. Manuel Cota Maximiliano”, 1965.
} 


\subsection{La segunda etapa: la crisis de Acción Católica 1965-1970}

Es conocido por todos que, a nivel nacional, sufrió durante esos años una aguda crisis que le llevará a una etapa de adocenamiento ${ }^{17}$. Fueron años de ruptura de la jerarquía eclesiástica, significando que muchos militantes jocistas y hoacistas empezaran a pasar al movimiento obrero.

Aunque la crisis también se dejó sentir en Cádiz y provincia, su impacto no fue $\tan$ fuerte como en otras latitudes gracias a que los movimientos contaban con el apoyo explícito del obispo Antonio Añoveros Ataún ${ }^{18}$, quien demostró en su pontificado una especial preocupación por lo que para él era una apremiante recomendación: la creación y florecimiento de las especializaciones obreras de la HOAC y la JOC, como organismos privilegiados dentro del mundo obrero para predicar la Doctrina Social de la Iglesia ${ }^{19}$, excusándoles para tal tarea, en cierta manera, de aquellos que las acusaban de temporalismo.

Así, se asiste en la diócesis gaditana a la siguiente paradoja: mientras que no se puede negar que tanto la HOAC como la JOC entraron, al igual que a nivel nacional, en un proceso de pérdida de identidad obrera en pro de un perfil más caritativo y asistencial y sin autonomía propia, desde el obispado se impulsan importantes actos de reconocimiento a los movimientos. El resultado de ese proceso es el siguiente: por un lado, la práctica real hizo que los militantes hoacistas fueran invitados a participar periódicamente en las

\footnotetext{
17 Respecto de la crisis de Acción Católica, siguiendo las ideas de TAMAYO, Juan José, "Historia del Postconcilio en España", Actas de la III Semana de Teología: La Misión de los cristianos en Andalucía a los veinte años del Concilio. Málaga, 1986, p. 36, estuvo provocada por la jerarquía, que obró con criterios más típicos de la etapa anterior al Concilio, concibiendo la Acción Católica como una participación más en el apostolado de la jerarquía. La razón era que los obispos acusaban a los movimientos de temporalismo, echándoles en cara la no sumisión a la jerarquía y a sus orientaciones. Entre la consecuencias de esta crisis Feliciano Montero y Antonio Murcia destacan la decepción de los militantes católicos de ver cómo la jerarquía eclesiástica no terminaba de negarse a mantener los privilegios que le otorgaba el nacionalcatolicismo, aumentando con ello su brecha con la Iglesia oficial y contribuyendo directamente tanto al aumento de la secularización de la sociedad en los últimos años del franquismo como a la desconfianza hacia al Régimen. MURCIA, Antonio, Obreros y obispos en el franquismo, HOAC,, Madrid, 1995 y MONTERO, Feliciano, La Acción Católica y el franquismo. Auge y crisis de la Acción Católica especializada en los años sesenta, UNED, Madrid, 2000.

18 Antes de alcanzar su puesto de obispo titular, Añoveros estuvo en la diócesis de Cádiz un largo periodo con el cargo de obispo coadjutor con derecho a sucesión, concretamente desde el 27 de octubre de 1954, justo cuando el entonces obispo, el conservador Tomás Gutiérrez Díez, elevó preces para que, a causa de su avanzada edad y delicada salud, se le otorgara un ayudante. Desde 1964, una vez fallecido D. Tomás, Añoveros pasa a ser el obispo titular de la diócesis hasta su nombramiento como nuevo obispo para la sede de Bilbao al final de la XV Asamblea Plenaria del Episcopado, a finales de 1971.

${ }^{19}$ Esto lo plasma nítidamente en su circular: "Por una Acción Católica eficiente y viva", de 27 de mayo de 1968. En su punto sexto señala que aunque la Acción Católica no es, ni mucho menos, una asociación de tipo reivindicativo, su actuación positiva puede derivar en exigencias que reclamen reflexiones y actitudes cristianas ante los hechos, por lo que no podrá acusársela de temporalismo, cuando trate de "imbuir de espíritu evangélico las diversas comunidades y los diversos ambientes", promoviendo la aplicación de los claros dictados de la justicia, de la verdad y caridad, esencialmente evangélicos. Boletín Oficial del Obispado de Cádiz y Ceuta (desde ahora BOOCC), junio 1968, pp. 200-203.
} 
reuniones de responsables de apostolado en las parroquias, encargándoseles, por ejemplo, responsabilidades de Cáritas, con lo que se perdía la perspectiva obrera de su actividad ${ }^{20}$. En definitiva, los militantes se convierten en meros ejecutores de las decisiones del párroco y, tal vez lo más sangrante para ellos, dejan de estar encarnados en los ambientes obreros. Pero, por otro lado, con todo el apoyo institucional, se asiste a los siguientes acontecimientos:

\subsubsection{La celebración del $1^{\circ}$ de Mayo de 1968}

Este acto público tuvo lugar en un emplazamiento más que simbólico: el patio interior de la Casa de la Iglesia $^{21}$. Es un acto público presidido por el obispo Añoveros y con la participación del Presidente Diocesano, Antonio Acevedo, del responsable de la JOC de Andalucía, Antonio Ibáñez, y, por no poder venir el presidente nacional Miguel Jordá, del miembro de la HOAC de Madrid Cayetano Hernández Fernández. Contó con una asistencia numerosa de trabajadores, de 150 a 200, venidos mayoritariamente de Astilleros, Aeronáutica y Bazán de San Fernando, quienes habían pedido insistentemente a los organizadores que pusieran cuidado, por los peligros que corrían por el acoso policial. Aceptando sus peticiones, se habilitó un servicio de vigilancia que intentó en todo momento impedir que la policía y los fotógrafos, que podrían vender más tarde sus fotos a las comisarías, pudieran entrar.

Respecto de la imagen que mostraba el lugar de celebración, el patio fue adornado con elementos obreros, llegándose a pintar en cartón un obrero ataviado con su mono azul de tamaño natural. Precisamente esta pintura azul con el tazón del engrudo para pegarlo, fueron las razones que invocaron la Brigadilla de la Policía Social para acusar fechas más tarde a los organizadores de pegadas de carteles obreristas por las calles, cuando una mañana registraron el local de la calle San Francisco propiedad de la Iglesia que la JOC y la HOAC usaban habitualmente.

\footnotetext{
${ }^{20}$ Como ejemplo, tal vez extremo de esta situación, se llegan a encargar a algunos hoacistas de actividades tan alejadas de sus anteriores quehaceres como recoger huevos para los pobres.

${ }^{21}$ Hay que poner en valor el gran impacto que tuvo como elemento aglutinador para la clase obrera y de visualización de su unidad la recuperación del $1^{\circ}$ de mayo desde 1959 como fiesta del trabajo, rechazando aquellos esquemas paternalistas asociados a la tradicional festividad de San José Artesano, instaurada en 1955 a instancias vaticanas. Esta fiesta del trabajo no tardó en erigirse en competencia directa de la celebrada por la Organización Sindical franquista y, debido a sus talante progresivamente reivindicativo, fue constantemente vigilada y perseguida por el Régimen. BERZAL DE LA ROSA, Enrique, "Contribución de la iglesia a la reconstrucción del sindicalismo de clase en España durante el Franquismo”, Historia Actual Online, 35 (3), 2014, p. 115.
} 
En pleno acto, llegaron en coches policiales tres inspectores con el Jefe de la Brigadilla y una patrulla de la Policía Armada, que se quedó a la puerta del edificio. Jamás hasta ese momento había ocurrido semejante suceso en un lugar de la Iglesia, y menos en uno tan venerado como ese, pues el local de la HOAC estaba debajo de la Capilla de la Santa Cueva. El organizador, Miguel Mougán, después de pasar el día en la comisaría de la calle Isabel la Católica, sobre las diez de la noche, viendo que no tenían motivos para inculparle, le dejaron libre. Momento que aprovechó para informar al obispo Añoveros, quién le dijo: "Aquí estaba cogiendo la dulleta (vestido sacerdotal como gabardina) para ir a la comisaría", y "o te dejaban libre o me tendrían que meter contigo"22.

\subsubsection{Desarrollo en Cádir del "XXI Consejo Nacional de la JOC de España y XI Consejo Nacional de} la JOCF"

Tuvo lugar desde el 17 al 21 de julio de 1968 y se celebró en el Seminario de Cádiz gracias a que Añoveros lo acoge, pues no habían encontrado facilidad para la organización en otras localidades. Respecto de este evento, el propio obispo dijo en sus palabras de presentación que había motivos de alegría: "Porque sois optimistas y enérgicos, porque amáis lo que yo más amo: el mundo de los sencillos y porque sois reflejo de la Iglesia primitiva" ${ }^{23}$.

\footnotetext{
22 AMM, Datos para una historia de la HOAC...:" $1^{\circ}$ de mayo en el patio interior de la Casa de la Iglesia, acto público", mayo de 1968.

${ }^{23}$ AMM: Apuntes para la Historia de la JOC...: "XXI Consejo Nacional de la JOC de España y XI Consejo Nacional de la JOCF, del 17 al 21 de julio de 1968. Seminario de Cádiz". El acto de inauguración, presidido por Añoveros contó también con los presidentes nacionales Enrique del Río y Julia Manzanera, Henk van Eekert, holandés, secretario europeo de la JOC Internacional y el Consiliario Nacional Vicente Amargós y, como auditorio, 130 delegados de España, entre los que estaban presentes jocistas de la emigración a Francia, Suiza, Bélgica y Alemania, y observadores de la JOC portuguesa, belga y francesa.

Como anécdota, señalar que al final de los Consejos y tras concluir la sesión de clausura contrajeron matrimonio el Presidente y la Tesorera Nacionales, Enrique del Río y Conchita Paracolla. Conocer el acto litúrgico y la celebración de la boda es un claro ejemplo del clima de militancia obrera que se respiró esos días por las instalaciones del obispado, y sobre todo en la capilla del Seminario Diocesano, donde se celebró el sacramento del sacerdocio con especial autorización del obispo, justo en el lugar donde se habían desarrollado las jornadas de los Consejos. El enlace matrimonial fue presidido por Alberto Revuelta Lucerga, sacerdote de la diócesis de Cádiz y antiguo Vicepresidente Nacional de la JOC, acompañado de varios consiliarios jocistas. El material escrito que se facilitó en la boda muestra interesantes detalles sobre el compromiso con la clase obrera: En la introducción se explicitaba el sentido de responsabilidad cristiana y obrera de los asistentes ante la clase obrera y el compromiso de fidelidad y de servicio a los demás y al mundo obrero; En las preces se pidió para que cada día creciera su servicio a la comunidad de los hombres, sobre todo a los más pequeños y a los más débiles. Y, especialmente, se pidió por todos los hogares obreros; Finalmente, el saludo de paz de la misa quiso ser demostración de solidaridad, y el compromiso de que los jocistas se sirvieran siempre mutuamente y al mundo obrero.
} 
Una de las tareas principales del Consejo fue el planteamiento y estudio de la acción jocista del año 1968-1969, centrada en el desarrollo integral del joven trabajador, sobre el cual expuso una larga ponencia el presidente nacional, quien señaló:

Se trata, de desarrollar todo el ser del hombre: su capacidad de amar, de ser libre, de enfrentarse libremente con responsabilidad ante la vida y la comunidad a que pertenece, sin presiones ni coacciones (...) Todo ello muestra al joven trabajador con una vocación de desarrollo, de completarse en su relación con los demás. Pero el joven trabajador está inmerso en una sociedad que actúa sobre él, no es dueño de su vida, de su futuro. En esta sociedad de consumo es el "objeto" y "destinatario" de la compra venta de necesidades creadas y no el "sujeto" protagonista de las relaciones sociales y de su propia promoción. ${ }^{24}$

\subsubsection{Inauguración del Centro Berchmans}

El 8 de diciembre de 1970 Añoveros presenta unas nuevas instalaciones para la HOAC y JOC en un lugar emblemático y simbólico: el salón del centro Berchmans, en la nueva Parroquia de San Francisco Javier, situada al lado de la factoría de Astilleros y su barrio de viviendas. El objetivo la creación de este nuevo centro de educación y formación fue, en palabras del obispo: "el puente entre la Iglesia y el Mundo Obrero". 25

El primero de los actos de mayor repercusión que se efectuó en las nuevas instalaciones fue la celebración de la Fiesta de los Trabajadores el $1^{\circ}$ de mayo de 1971, que posibilitó la reunión de hoacistas y jocistas con unos 40 obreros de Astilleros y de la empresa Aeronáutica que recordaron los orígenes del movimiento obrero y hablaron de la acción obrera en el momento que les tocaba vivir. Este acto tuvo un desenlace inesperado; y es que a su conclusión, varios coches policiales ocuparon las entradas de las tres calles adyacentes al centro, cerrando el cerco hasta la puerta de la parroquia, a la que llamaron repetidas veces. Al ver que ya no había nadie, pues los reunidos se encontraban ya fuera observando asombrados el despliegue, se marcharon ${ }^{26}$.

Para acabar con lo que significó para Cádiz la ya planteada crisis de la Acción Católica, no hay mejor forma de hacerlo que estudiar la respuesta que los militantes ofrecieron, en agosto de 1969, al cuestionario recibido sobre: “Los Movimientos de Acción

\footnotetext{
${ }^{24}$ BOOCC, agosto de 1968, p. 279

25 AMM, Datos para una historia de la HOAC...: "Inauguración de la nueva parroquia de San Francisco Javier", 8 de diciembre de 1970.

${ }^{26}$ El día del trabajo de 1972, ante la experiencia de ese año, los hoacistas y jocistas decidieron celebrarlo con algunos trabajadores en un sitio más seguro, optando por los salones del obispado, que era la sede de Acción Católica. Ese año no hubo incidentes ni molestias de la policía.
} 
Católica" ${ }^{27}$; encuesta que se envió a todos los obispos diocesanos para su cumplimentación por los movimientos de la JOC y la HOAC y que quería validar o no la tesis previa que afirmaba que el movimiento de Acción Católica y sus movimientos especializados obreros pecaban del ya aludido "temporalismo". El análisis de las respuestas al cuestionario es de un interés mayúsculo para conocer la realidad del momento, tanto de su reconocimiento y positiva valoración en los entornos obreros por parte de los trabajadores, como lo crítico de sus posturas hacia la propia Iglesia (salvando de la quema a su obispo Añoveros) y la nueva realidad de la Acción Católica. Los datos más relevantes que se facilitaron fueron, estructurados por bloques y de forma resumida, los siguientes:

a) Respecto de los valores humanos y la ideología de los militantes y dirigentes de los movimientos.

Se reconoce el grado de militancia obrera y sindical cuando citan que varios de ellos han sido elegidos por sus compañeros para cargos de responsabilidad sindical y que, de entre ellos, por lo menos siete eran entonces enlaces provinciales.

b) Respecto de la militancia política y sindical.

Se señaló expresamente que en dirigentes y militantes cada uno elegía el comportamiento y el camino temporal que le parecía oportuno. Así, ponen el ejemplo de que en recientes problemas sindicales ha habido hoacistas "en uno y otro lado". De forma práctica, para conocer el influjo real de los movimientos en el mundo del trabajo, señalan que tanto la HOAC y la JOC no era solo conocidas en los ambientes de trabajo, sino que gozaban de bastante prestigio. Así, ponían el ejemplo de que en Astilleros de la Bahía las fuerzas activas del mundo obrero eran, en este orden: por un lado, los comunistas, y por otro, los hoacistas.

c) Actitud y posición de los militantes respecto a la Jerarquía.

Si en un primer momento señalan que la observan con respeto como miembros necesarios de la Iglesia, más adelante lamentan su lejanía de los problemas dolorosos del mundo obrero. Así, reconocen su deseo de ver la Iglesia signos y gestos de auténtica pobreza, de libertad evangélica, como la de los Apóstoles, dicen, ante el poder político y económico.

\footnotetext{
${ }^{27}$ AMM: Apuntes para la Historia de la JOC...: "Cuestionario de la CEAS sobre los Movimientos Obreros de Acción Católica". A destacar que, sobre la existencia en la diócesis de los movimientos de HOAC, HOACF, JOC y JOCF y número de equipos y de militantes, los encargados de cumplimentar el cuestionario introducen el intencionadísimo comentario de que sus miembros: "más que militantes, son una piadosa asociación".
} 
d) Opinión de los obreros de los movimientos apostólicos.

Extremadamente negativos se muestran al respecto, llegando a señalar que el pensamiento principal que tienen es que están haciendo "el ridículo" porque tarde o temprano la Iglesia los abandonará, ya que son de la idea de que con la Iglesia no se va a ninguna parte por estar siempre del lado de los poderosos. Así, se reafirman en la opinión de que a la Iglesia, como el poder político y económico, solo le interesan los obreros "domesticados".

Igual de críticos y negativos son respecto de la relación con la Acción Católica emanada de los nuevos estatutos, llegando a decir con rotundidad que los militantes no están dispuestos a aceptarlos y trabajar según estas nuevas disposiciones, ya que imponen tantos controles que suponen gran desconfianza del laicado cristiano obrero. Así, acaban la crítica, dicen tener la impresión de que lo que se pretendía, consciente o inconscientemente, era callar "las voces proféticas del mundo obrero que reclaman la justicia de Dios, para no disgustar a los poderosos del Régimen”.

Como conclusión, el equipo gaditano informa de que convendría pensar en el dolor profundo de militantes y dirigentes, que se entregaron noblemente a la tarea evangelizadora, ante una actitud de la Jerarquía que parecía excesivamente jurídica y menos pastoral con los movimientos obreros, señalando que sentían desconcierto al comprobar que pareciera que se quisiera quererse en España ponerles más exigencias que las que ponía el propio Sumo Pontífice. Lo grave de esta dinámica era que:

(...) ocurre en un momento en que, por primera vez en toda la Historia de la Iglesia Española se habían conseguido grupos y organizaciones católicas que siendo fieles a Cristo, eran a la vez aceptados, respetados y admirados por el mundo obrero y por los militantes obreros no cristianos al ver que luchaban por los justos valores de la reclamación obrera y por la promoción colectiva de la clase trabajadora.(...) Esta nueva y triste situación retrasaría irremediablemente años y años la recristianización de la clase obrera, ya que llevarían muchos años y muchos sacrificios volver a conseguir la confianza que había empezado a despertarse entre los trabajadores para con la Iglesia. ${ }^{28}$

\section{EL ACOSO DE LAS AUTORIDADES GUBERNATIVAS}

La entrada de la década de los años setenta significó, al igual que en el resto de España, el acoso policial a los movimientos especializados, contribuyendo a la disminución progresiva de militantes y simpatizantes.

28 Ibidem, p. 3. 
Este clima represivo no solía manifestarse de forma tan flagrante como en los hechos citados acaecidos en las celebraciones del primero de mayo, sino que se manifestaba de una forma más sibilina, por medio de una continua visita a los familiares de los militantes. La estrategia disuasoria era la siguiente: llegaban y preguntaban a los familiares (a los que aseguraban que se trataba de un puro trámite) los datos del trabajador, en qué empresas trabajaban y sobre la organización apostólica a la que pertenecía. La cuestión era que por muy rutinarias que fueran estas vistas policiales, inquietaban a las familias y ponían un cerco de recelo y sospecha en su entorno íntimo.

Por entonces, circulaban por algunos lugares frecuentados por los equipos hoacistas, una serie de documentos internos que a modo de manual de hoacista, aconsejaban cómo había de desenvolverse éste en esa microsociedad que significa el propio barrio o parroquia donde vivía, como aquel que incluía las siguientes instrucciones:

Postura del militante: Debe ganar el prestigio en el barrio, es decir, hacerse notar por sus virtudes, por si algo ocurre por la autoridad gubernativa (...). Ganar el cariño y la estima de la gente del barrio, dando muestras de espíritu comunitario de servicio, de defensa del barrio. Debe construirse un propio prestigio, o sea, que lo respeten en el barrio. Que su seriedad y honradez sea un hecho en todo momento. Debe aparecer como protector de unión o de la unidad con los trabajadores y del barrio. Visitar a las familias, etc. (...) Todo esto ¿por qué? Porque de haber problemas con la autoridad gubernamental, ha de ser ésta la que quede mal. La que sea reprobada por los vecinos y no el militante. Porque es fundamental hacer eso, para un militante verdaderamente revolucionario. El militante debe conocer perfectamente, procurar, los estudios jurídicos de las asociaciones, elementos reaccionarios, elementos de grupos políticos o sindicales, que puedan vivir en el barrio 29 .

\section{LA FIGURA DEL CONSILIARIO}

Estaba prevista fundamentalmente para que conectara al movimiento especializado con la jerarquía eclesiástica, autorizando o no las decisiones que se tomaran en su funcionamiento, lo que no quería decir que fueran los responsables de la ejecución de las acciones previstas en su actividad, ya que éstos eran siempre los seglares. ${ }^{30}$

Para dotar a la militancia de consiliarios, en primer lugar, había que facilitar un punto de encuentro entre aquellos curas interesados en la problemática obrera y los movimientos especializados. Ejemplo de esto puede ser el encuentro: "Cursillo de Pastoral Jocista para sacerdotes”, celebrado en la Casa Diocesana de Ejercicios de Cádiz del 23 al 27

\footnotetext{
${ }^{29}$ En AHPC, GC, OPyDC, caja 2941. Carpeta 3.4. AR: Nota informativa de la policía de 25 de abril de 1972.

30 COMISIÓN NACIONAL DE LA HOFAC: Cómo se inicia un Centro HOFAC, HOFAC, Madrid, 1958, pp.18-19.
} 
de enero de $1967^{31}$, en el que participaron el consiliario nacional, Vicente Amargós, el diocesano, Miguel Mougán, y el responsable de Zona Manuel Cota.

En estas jornadas, por un lado, se hizo un análisis pormenorizado de toda la problemática y condicionamiento de la clase obrera: vivienda, niveles económicos, condiciones de trabajo, sentido de clase, emigración e inmigración, diversiones, vida social, niveles culturales, motivaciones humanas y religiosas en su vida, etc. Y por otro, se analizaron los condicionantes o elementos alienadores de la clase trabajadora, intentando proyectar con claridad la misión que tenían los participantes como pastores:

Llevar la acción pastoral hacia las personas, y a éstas de forma individual, con sus nombres y en sus realidades concretas, atentos a ellas y de forma dinámica (...) hombre de Dios, profeta, educador de la fe, encarnación en la vida y acontecer humanos de la Palabra de Dios. ${ }^{32}$

Pero desde un punto de vista histórico, hay que esperar al lunes 16 de diciembre de 1968 para asistir a la primera reunión de todos los consiliarios HOAC y JOC de la diócesis. El encuentro, convocado a instancias del propio Añoveros, tuvo lugar en la Casa de Ejercicios de San Roque y asistieron: José Araujo González (cura obrero de la Orden de los Frailes Menores Capuchinos, Párroco de la Divina Pastora de Cádiz), Juan de Dios Regordán Domínguez (Coadjutor de la Parroquia de San José de Ceuta), Manuel Gaitero Rosado, (cura de la Parroquia de San Sebastián de Puerto Real), Enrique Pérez Cayetano (Coadjutor de la Parroquia de la Divina Pastora de San Fernando), Alberto Revuelta Lucerga (temporalmente realizando estudios en Madrid), Carlos Vidal López de Arbina Echevarría (cura obrero extradiocesano perteneciente a la diócesis de Vitoria, Coadjutor de la Parroquia de San Bernardo Abad, La Línea), Manuel Montado Galindo (Párroco de Nuestra Señora de Lourdes de Cádiz), Camilo García Valenzuela (Parroquia de San José de Cádiz), Jesús Maeztu y Gregorio de Tejada (Párroco de la Asunción, Cádiz), José Ramón Pérez Perea (cura obrero extradiocesano perteneciente a la diócesis de Vitoria, Parroquia de San Bernardo Abad, La Línea), Juan Cejudo Caldelas (cura obrero, entonces presbítero en Tarifa) y Miguel Mougán. Se trata de una reunión en la que se actuará:

\footnotetext{
31 AMM: Apuntes para la Historia de la JOC...: "Cursillo de Pastoral Jocista para sacerdotes. Casa Diocesana de Ejercicios (CÁDIZ)", 23-27 de enero de 1967. Es interesante conocer que en el transcurso de las jornadas, el día cuarto concretamente, se integró el propio obispo Añoveros en el estudio y debate de las jornadas, manifestando su preocupación por una verdadera pastoral obrera de la diócesis, para la que señaló como elemento básico, porque dijo que sin él no sería posible un serio esfuerzo evangelizador en el mundo obrero gaditano, la formación de grupos JOC. BOOCC, febrero de 1967, p. 154.

32 BOOCC, febrero de 1967, pp.153-154
} 
(...) como en las demás reuniones, con sinceridad para construir la respuesta al mundo obrero sin halagar ni ocultar la verdad, con sentido estricto de la corresponsabilidad.

Todo ello sin perder de vista la meta: evangelización del mundo obrero ${ }^{33}$.

La estructura de esta reunión recordaba en cierta medida a la metodología de la revisión de vida obrera: se empezó por una primera parte denominada "realidades", para pasar a una segunda llamada "dificultades", y terminar con otra tercera a la que catalogaban de "exigencias". Respecto de las realidades, cada uno de los consiliarios comunicó al obispo y a los presentes, tras informar sobre el número de hoacistas, jocistas y simpatizantes en su territorio, la realidad obrera que observaban en su mundo circundante, la visión que tenían los obreros de la Iglesia jerárquica diocesana y la realidad de las relaciones laborales. De entre las aportaciones más destacables se pueden citar las siguientes:

\section{RESPECTO DE LA CLASE OBRERA:}

Los jóvenes obreros rechazaban a la Iglesia, mientras que los menos jóvenes la acusaban tanto de estar con los poderosos como de que los curas se callaban y no denunciaban situaciones injustas.

La prensa ofrecía noticias negativas contra los obreros (en el mejor de los casos, pues se llega a señalar que "la verdad no se dice") con el consecuente miedo para los mismos al recibir el mensaje constante de "no te metas" a intentar solucionar problemas o injusticias.

Desinterés por lo político de la clase obrera, lo inhumano de los horarios de sus trabajos y ausencia de organizaciones obreras.

Existencia de dos miedos fundamentales en los trabajadores: al despido y a la represión policial. Al respecto, se afirmó que a través de terceras personas la propia policía había creado un ambiente de represión. El ambiente de fuerza creado por la policía armada y la guardia civil, les permitía a los patronos sus abusos por "psicosis de dominio" de los obreros.

Dificultades de los jóvenes que se dedican a los trabajos en la mar para embarcarse por el caciquismo existente en el sector.

Respecto de la población de mayor edad (de los que se llegó a decir que estaban "quemados por la guerra"), aún no estaban resueltos sus problemas fundamentales de trabajo y vivienda, siendo un colectivo de gente que se considera "vencida".

La empresa fomenta la insolidaridad entre los trabajadores y el miedo de los mismos a actuar.

Del desempleo en la provincia se llegó a concluir directamente que: "no hay trabajo".

Se confirmó "el problema aplastante" de la ausencia de la vivienda y del hedonismo de la juventud obrera, que buscaba continuamente la evasión de sus problemas cotidianos mediante el sexo, la diversión, ver mucha TV, etc.,

33 AMM, Datos para una historia de la HOAC...: "Reunión de equipo a instancias del Sr. Obispo Antonio Añoveros", 16 de diciembre de 1968, p. 2. 
RESPECTO DE LA IGLESIA DIOCESANA:

Se criticó duramente la aparición pública de autoridades civiles y eclesiásticas en actos públicos.

Existencia de "amarillismo" en la diócesis. A esta inercia podía colaborar el clero local, que se oponía verdaderamente a un laicado obrero, producto de la falta de atención generalizada a la clase obrera. Esto les hacía cómplices de la injusticia por impedir la acción obrera.

Prejuicios de los obreros respecto de la Iglesia afirmando que los trabajadores sólo buscan a los curas para que les "saquen las castañas del fuego".

Hipocresía existente en la vida eclesiástica gaditana respecto del mundo obrero (se llega a poner el ejemplo ilustrativo de que la propia iglesia diocesana tiene una imprenta en la que los aprendices son explotados).

Se explicitó la "atadura geográfica que significaba la parroquia para la intervención", aunque señalando que se debía aprovechar el oportunismo de la acción de la Iglesia en su dedicación a los pobres como una forma de alejar la imagen de que ésta detentaba el poder.

\begin{tabular}{|c|}
\hline RESPECTO DE LA HOAC Y LA JOC DIOCESANA: \\
\hline $\begin{array}{l}\text { Se profundizó en el concepto de caridad asistencialista como peligro en que podía caer el } \\
\text { movimiento de la HOAC }\end{array}$ \\
\hline $\begin{array}{l}\text { Se puso de manifiesto que el exceso de trabajo de los obreros hoacistas, de } 13 \text { o } 14 \text { horas } \\
\text { diarias, les dejaba "sin humor para un esfuerzo militante". También se aludió a un sector } \\
\text { concreto: ausencias a las reuniones de los hoacistas trabajadores de la mar, ya que a veces } \\
\text { marchan a faenar hasta por tres meses. }\end{array}$ \\
\hline $\begin{array}{l}\text { Se criticó el poco compromiso existente por parte de los hoacistas, que "insisten más en la } \\
\text { formación que en la acción". }\end{array}$ \\
\hline
\end{tabular}

Tabla núm. 2: Conclusiones de la primera reunión de todos los consiliarios con la presencia del obispo: Realidades.

Fuente: elaboración propia a partir de las actas recogidas en el archivo personal de Miguel Mougán.

Con ese serio y exhaustivo análisis de la realidad se pudieron explicitar una serie de dificultades con las que los consiliarios y la propia iglesia diocesana, se encontraban a la hora de trabajar con la clase obrera gaditana, recogiéndose de la propia reunión las siguientes conclusiones al respecto:

a) Hay anti-testimonio de los curas.

Recordaron que hay sacerdotes que "viven bien y el obispo lo sabe". Como ejemplo se citó el caso de cómo que se gastaron 10 millones de pesetas en arreglar una Iglesia mientras faltaban viviendas en el barrio u otras no tienen saneamientos. En el mismo orden de cosas, recuerdan que hay curas con ahorros, varios pisos, vendiendo propiedades, etc. 
b) Falta de seria preocupación pastoral por los obreros.

Hundiendo las raíces de esta realidad en el miedo existente a que pensar en ellos significaba hacer política: preocuparse por la clase obrera solo podría complicarle al cura la vida. Esta situación la resumieron en: "Sí a lo social, pero con hondo miedo".

c) La Iglesia como conjunto diocesano no muestra a Cristo.

Esto es debido a que la Iglesia posee complejos parroquiales, escuelas de religiosas, palacios, un tesoro en la catedral, etc., que ofrece una imagen de "Iglesia Poder" sin rostro evangélico. Esto llevaba a una sensación de decepción y desconfianza para con la Iglesia, que, según los reunidos, también tenía su reflejo en la crisis de los movimientos especializados obreros de la Acción Católica con la jerarquía.

d) El sentido de impotencia de la clase trabajadora.

Pensaban que ni el Estado ni la empresa "deja hacer", poniendo en marcha sus recursos a su alcance: represión, horas extras, trabajo a turnos, expulsión, policía en centros de trabajo y represión policial contra la JOC y la HOAC.

e) "Los colosales tentáculos de las empresas":

Hacían alusión al paternalismo con el que actuaban las mayores empresas gaditanas como astilleros, que eran las encargadas de promocionar vivienda, economato, escuelas, etc., convirtiéndose en una de las razones por las que el trabajador no se levantaba contra las injusticias.

f) El materialismo (el confort) inventado por el capitalismo.

Comprar frigoríficos, TV, vivienda, etc., llevaba aparejado, entre otras consecuencias el fomento de las horas extras, que, a su vez, no permite tener ganas al obrero para involucrarse en nada más.

Con el anterior análisis, completado por el apartado de dificultades, el grupo de los allí reunidos se vio capacitado para realizar una serie de prescripciones con las que hacerles frente y que debían ponerse en práctica bajo una nueva premisa: "la autoridad como servicio", de entre las que destacaron:

- Bajo el principio general del deber de la Iglesia de denunciar las injusticias, los militantes y simpatizantes debían buscar cauces para el compromiso temporal bajo la consigna: "la fe vitaliza la acción revolucionaria". A ello debía colaborar el consiliario, centrándose en la tarea oculta, callada, de educarles en esa dirección, teniendo en cuenta lo sacrificado y lento de la tarea, renunciando para ello, de 
auto erigirse como líderes y evitando toda tentación de "amarillismo". Para ello, aprovechando la presencia física del obispo, se le exigió un plan de apostolado obrero, pensado con la aportación de todos los curas y seglares involucrados, y que debiera tomarse en serio y no ser como algo de "devoción extraordinaria".

- Que haya gestos que sean signos de desprendimiento, para compartir la suerte de los pobres. Signos de sacerdotes, de parroquias, del obispo y de la diócesis. Así, se debía desechar la actitud de ambigüedad en hechos concretos, por ejemplo, protegiendo la actitud de aquellos curas que no vivían con signos de pobreza.

- Necesidad de definir los campos de competencia entre lo civil y lo eclesiástico, dando para ello pasos visibles y concretos en la curia diocesana, ya que, "seguir en esta postura inmovilista puede dar lugar a deserciones". Tomar la decisión de que el obispo y los curas no aparecieran como autoridades en los actos públicos, sobre todo políticos, sino que, en el caso de estar presentes, deberían hacerlo como simples ciudadanos. Así, por ejemplo, se habría que abandonar las bendiciones en las botaduras de barcos ya que era una forma de apoyar implícitamente las lamentables relaciones laborales existentes en los propios astilleros.

- La necesidad de los sacerdotes en el trabajo. Algunos sacerdotes deberían estar en el trabajo en equipo con otros, ya que este sería el claro testimonio de la preocupación de la Iglesia por el trabajo obrero.

En cierta medida, este encuentro de consiliarios representa fielmente la evolución de la Iglesia y el impacto del Concilio Vaticano II en la evolución del clero, y sus conclusiones se adelantan a la Asamblea Conjunta de $1971^{34}$. Así, coinciden con las conclusiones generales de la asamblea a nivel nacional de asumir la evangelización y el compromiso de la promoción y liberación humana como componentes esenciales de la Misión de la Iglesia, reconociendo la urgencia de caminar hacia una iglesia misionera, libre y profética frente al poder, inclinada hacia los alejados y al servicio de los más pobres.

Baste para ello recordar la Ponencia "Iglesia-Mundo" a nivel diocesano, en la que se abordó con decisión la problemática derivada de que algunos curas no tomaran una posición decidida frente a situaciones injustas en los aspectos sociales, económicos y políticos, actitud que no debía tolerarse porque significaba reproducir los tópicos acerca de la Iglesia y su cercanía con los poderosos. Para ello se pidió que el clero se mantuviera al

\footnotetext{
34 Para completar el contexto de la asamblea, es útil leer la introducción de la obra de LABOA GALLEGO, J.M., El Postconcilio en España, Ed. Encuentro, Madrid, 1988, para conocer cómo significó la recepción consciente y gozosa del concilio en la Iglesia española, mostrando la nueva conciencia tanto de la Iglesia como de los laicos de su concepción de creyentes y de su responsabilidad eclesial.
} 
margen de aquellos actos de evidente signo político en los que debía compartir espacio con representantes gubernamentales ${ }^{35}$. También se solicitó la necesidad de que el obispo reflexionara, junto a su clero y los laicos responsabilizados, sobre eventuales hechos y situaciones condenables (y las causas que los provocaron) para que, seguidamente, pudieran pronunciarse con libertad y valentía sobre los mismos con una cierta unidad de acción. Una asamblea conjunta que para la curia gaditana, significó "el triunfo aplastante del bloque progresista sobre el moderado" 36 , bloque, el primero, en el que hay que situar a los consiliarios de los movimientos obreros objeto de este estudio.

\section{CONCLUSIONES}

Los mandatos apostólicos de los movimientos especializados diocesanos, ilustrados nítidamente con el reivindicativo papel de sus consiliarios, demuestran cómo en momentos de ilegalización de partidos políticos y sindicatos lucharon, con la inestimable aquiescencia del obispo Añoveros, por promocionar a una clase trabajadora gaditana deficitaria de conciencia de clase. El movimiento obrero ahora veía entre sus compañeros de tajo a representantes de una Iglesia, a la que tradicionalmente acusaban de estar al lado de los poderosos y ser cómplices del sistema, luchando por sus intereses, contribuyendo con ello a debilitar la fuerza del nacionalcatolicismo oficial en la diócesis.

\footnotetext{
${ }^{35}$ Respecto de alejamiento de actos políticos, la resolución fue aprobada por 38 votos a favor, 8 en contra y 4 abstenciones, y respecto de los actos civiles, la resolución aprobada por 32 votos a favor, 14 en contra y 4 abstenciones. BOOCC, agosto 1971, p. 300 bis.

36 AHPC, G.C., OPyDC. Caja 2942. Carpeta 3.4. A.R.: "Sobre el trascurso de la Asamblea de Obispossacerdotes”, Nota Informativa de la Policía de 16 de julio de 1971, p. 3.
} 